\title{
EMOTICONS DO FACEBOOK: ANALISANDO A DEMARCAÇÃO DE SENTIMENTO E ENGAJAMENTO DO CONSUMIDOR PELA MÍDIA SOCIAL
}

\author{
Facebook emoticons: analyzing feeling's demarcation and \\ consumer engagement through social media
}

\section{Emoticons de Facebook: analizando a la demarcación de sentimiento y compromiso del consumidor por los medios sociales}

\author{
Wesley Moreira Pinheiro \\ Pontifícia Universidade Católica de São Paulo, São Paulo, Brasil \\ Doutorando e mestre em Administração pela Pontifícia Universidade Católica de São Paulo. Professor e \\ pesquisador da Faculdade Paulus de Comunicação. \\ E-mail: wesleymp@gmail.com
}

RESUMO Este estudo faz uma análise do uso dos emoticons do Facebook para demarcação de emoções como forma de conversação e engajamento em mídias sociais. Os resultados apontam para os agrupamentos dos emoticons em relação aos sentimentos expressos, revelando a impossibilidade de se criar uma escala métrica que mensure a intensidade de todas as reações, porém torna-se mais clara a potencialidade de análise de engajamento em virtude dos sentimentos expressos.

PALAVRAS-CHAVE Engajamento em mídias sociais, Interatividade em mídias sociais, Comportamento do consumidor.

\begin{abstract}
This study analyse the use of Facebook emoticons to demarcate emotions as a form of conversation and engagement in social media. The results point to groups of emoticons in relation to the expressed feelings, revealing the impossibility of creating a metric scale that measures the intensity of all reactions, although, it becomes clearer the potentiality of engagement analysis due to the expressed feelings.
\end{abstract}

KEYWORDS Engagement in social media, Interactivity in social media, Consumer behavior.

RESUMEN Esta investigación trata de un análisis sobre el uso de los emoticons de Facebook para demarcación de emociones como forma de conversación y envolvimiento en medios sociales. Los resultados apuntan a las agrupaciones de los emoticons con relación a los sentimientos expresados, revelando la imposibilidad de crear una escala métrica que mida la intensidad de todas las reacciones, pero se hace más clara la potencialidad de análisis de envolvimiento en virtud de los sentimientos expresados

PALABRAS CLAVE Compromiso en los medios sociales, Interactividad en medios Sociales, Comportamiento del consumidor. 


\section{INTRODUÇÃO}

Há tempos ouvimos e lemos sobre as transformações sociais e culturais potencializadas primeiramente pela internet, depois pela web e, em seguida, pelas mídias sociais. É devidamente notável que "nossas ferramentas de mídia social não são uma alternativa para a vida real, são parte dela” (SHIRKY, p. 37, 2011) e, para isso, basta levarmos em consideração que o Facebook, por exemplo, atingiu a marca de 2 bilhões de indivíduos cadastrados e ativos pelo mundo no ano de 2017 (NOAWK; SPILLER, 2017). Desse número, mais de 65 milhões são de perfis oficiais de marcas, dos quais mais de 5 milhões são anunciantes ativos (FACEBOOK..., 2017a), que investem em publicidade e propaganda de seus conteúdos, produtos e serviços.

Para termos uma noção de como as práticas interativas nessa mídia estão ligadas às nossas rotinas de comunicação, tomamos como exemplo os dados divulgados pelo Facebook sobre a interatividade dos brasileiros durante o período de Carnaval no ano de 2017. No Brasil, cerca de 63 milhões de pessoas interagiram mais de 710 milhões de vezes com conteúdo relacionado à folia entre os dias 24 de fevereiro e $1^{\circ}$ de março (CARNAVAL..., 2017).

Essas interações podem ser agrupadas e medidas pelo volume de curtidas, comentários e compartilhamentos. "As marcas encontraram nas mídias sociais uma nova forma de ouvir, dialogar, e observar o comportamento do consumidor" (MOTTA, 2016, p. 111). Por isso, apoiamonos na reflexão de Castells (2015) discutindo a internet, a web e toda a tecnologia contida nesse ambiente não como uma mídia tradicional como a televisão, mas como uma mídia interativa, na qual o consumidor é quem decide o que consome e como se relaciona com seu conteúdo.

Compreender como as mídias sociais atuam no processo de interatividade e relacionamento entre consumidor e conteúdo faz parte da inquietação desta investigação, pois Salustiano (2016) afirma que as mídias sociais são uma mina de dados agrupados em mensagens que circulam pelo ambiente em rede, no qual os indivíduos podem expressar suas opiniões e posicionamentos até chegar no engajamento.

A fim de diversificar o processo de interatividade de seus consumidores, no início de 2016 o Facebook lançou cinco reações, aqui tratadas como emoticons ${ }^{1}$, com a função de melhorar a forma de expressão e relacionamento de seus usuários com o conteúdo que consomem e produzem. Como faz parte das finalidades do monitoramento de mídias sociais a análise de sentimentos, reações e engajamento (ZANDAVALLE, 2016), esta investigação questiona: como os emoticons podem ser agrupados e analisados a fim de demarcar sentimentos e engajamento dos consumidores em relação aos conteúdos que acessam?

Tomamos como objetivo geral analisar o uso dos emoticons do Facebook como forma de expressão de sentimentos capazes de potencializar o engajamento. O artigo, então, será estruturado em três partes: (i) revisão da literatura sobre o uso de emoticons, conversação em rede e engajamento com o foco na mídia social Facebook; (ii) uma descrição dos procedimentos metodológicos, da coleta de dados e a análise dos resultados; e (iii) considerações finais e apontamentos de limitações e desdobramentos da pesquisa.

1. Sabemos que há outras formas de denominar esses ícones, como emojis, por exemplo. Porém tomaremos como base o termo emoticon, defendido por Paiva (2016) como uma forma de união entre as palavras emotion (emoção em inglês) + icon (ícone em inglês). 
1. Color Icons

Flat Color, Face Style 1

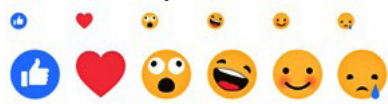

2. Color Icons + Color Variations

Flat Color, Face Style 1

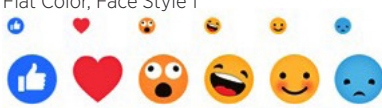

3. Color Icons w/ strokes

Color faces with distinct facial expressions

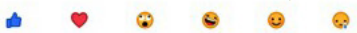

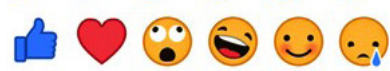

4. Variations in Shape \& Color

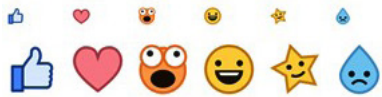

\section{REAÇÕES E EMOÇÕES: A BUSCA DO FACEBOOK PARA DIVERSIFICAR OS DADOS DE CONVERSAÇÃO}

Criado no ano de 2004, o Facebook passou a ser uma das principais mídias sociais do mundo em volume de usuários e de investimento publicitário. Atualmente é o terceiro endereço eletrônico (Uniform Resource Locator - URL) mais acessado pelos brasileiros na internet e a segunda mídia social (TOP..., 2017). Além dos 102 milhões de brasileiros que possuem cadastro nessa mídia social (102 MILHÕES..., 2016), podemos destacar o fato de que em 2016 o Facebook obteve o primeiro lugar no ranking dos "Veículos mais admirados no Brasil", pesquisa realizada com 809 profissionais do mercado de publicitários e anunciantes brasileiros, que envolveu categorias como formato comercial e engajamento (FACEBOOK..., 2017b).

Mídias sociais propagam informações (SOARES; MONTEIRO, 2015) e por meio da participação no Facebook empresas buscam consumidores dispostos a disseminar seus conteúdos (TUBENCHLAK et al., 2015), criando estratégias de comunicação direcionadas a seus públicos específicos para obter um número significativo de "curtidas” (TOALDO; RODRIGUES, 2015). O botão "curtir" foi disponibilizado em 2009 (ORTEGA, 2016), e em 2016 foram adicionados cinco ícones, chamados de reactions por Geoff Teehan, diretor de design do Facebook, com a finalidade de ampliar as formas de expressão dos usuários (TEEHAN, 2016).

Durante o processo de desenvolvimento desses ícones, segundo Teehan (2016), era necessário que o conjunto de reações fosse entendido universalmente e capaz de se alinhar à vida real, evitando o binarismo "gostei/não gostei". A busca para determinar quais reações seriam usadas incluiu a aplicação de questionários em diversos países pelo mundo, com usuários e profissionais do Facebook (TEEHAN, 2016) realizando vários testes de design com ícones como "curtir", "amei”, "haha”, "uau”, "triste”, "raiva”, “confuso” e “eba” (Figura 1).
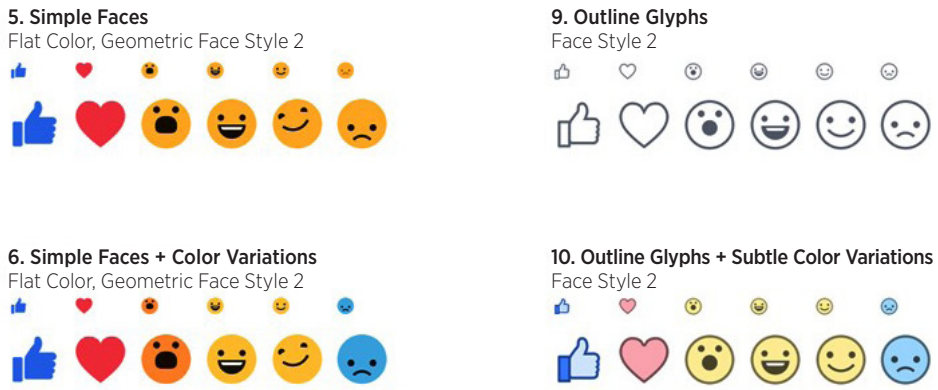

10. Outline Glyphs + Subtle Color Variations Face Style 2
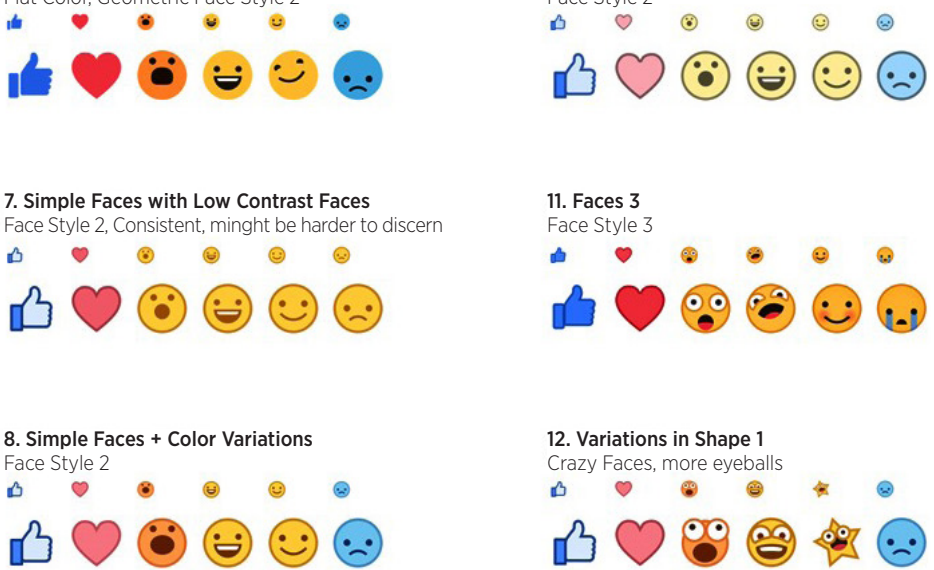

Figura 1. Possibilidades estudadas para as reactions do Facebook.

Fonte: Teehan (2016). 
As "reações" não deveriam tornar complexos os comportamentos e as pesquisas apontavam que seria necessário o uso de cinco a dez emoticons (TEEHAN, 2016), porém isso inviabilizaria a disseminação desses ícones. Os testes foram seguindo até chegar no formato atual, capaz de ser compreendido em qualquer cultura, ocidental ou oriental (Figura 2).

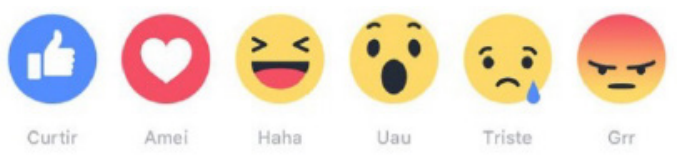

Figura 2. Reações atuais do Facebook. Fonte: "Amei"... (2016).

Essa busca do Facebook por disponibilizar reações capazes de sintetizar as emoções e a percepção do consumidor em relação ao conteúdo que se está consumindo ou produzindo se justifica a partir do momento em que levamos em consideração dois elementos: a diversidade de dados sobre as emoções e a facilidade de perceber a emoção por meio de uma figura como emoticon.

O Facebook revelou que, diariamente, são mais de 175 milhões de "amei" e 800 milhões de "curtir" utilizados como formar de reagir aos conteúdos disponíveis (NOAWK; SPILLER, 2017). Para Rico (2016), o emoticon "curtir" é uma ação de envolvimento social, traduzida por meio de um clique que revela uma função emocional, porém melhor explorada a partir da inclusão das cinco novas reações. As práticas sociais de linguagem acontecem de forma complexa, estão em constante processo de mudança e se adaptam às tecnologias digitais, que não deixam de possibilitar o uso de palavras, entonação e expressões faciais (PAIVA, 2016), potencializando as conversações por meio de mídias sociais, como o Facebook.

As conversações nas mídias sociais se dão pela apropriação dos recursos das ferramentas. Em relação ao botão “curtir”, propiciam uma forma de tomar parte de uma conversação sem fazer parte dela, sem muito esforço por parte do consumidor (RECUERO, 2014). Podemos considerar que a diversificação dada pelos emoticons muda esse cenário, pois o consumidor deixa mais clara e evidente sua emoção/reação em relação ao conteúdo, criando uma conversação mais clara e intensa, não mais restrita a uma simples ideia de apoio, podendo ser até de repúdio.

\section{O ENGAJAMENTO POR MEIO DA CONVERSAÇÃO EM TORNO DOS EMOTICONS}

As características das ferramentas de mídias sociais delineiam as práticas conversacionais (TOALDO; RODRIGUES, 2015). A interação, uma das funções básica de uma mídia social, é um fundamento primário no estabelecimento das relações sociais em que o consumidor pode se expressar, muitas vezes gerando engajamento (SOARES; MONTEIRO, 2015).

A interação se dá por um diálogo entre aqueles que fazem parte de uma conversação, possibilitando a captação das respostas como reação à ação do outro (TOALDO; RODRIGUES, 2015), porém necessita da interatividade como objeto reativo ao estímulo dado por meio do conteúdo trabalhado pelo Facebook. O grau de interatividade pode 
ser analisado pelas possibilidades de apropriação e personalização da mensagem recebida e pela reciprocidade da comunicação (LÉVY, 1999; TOALDO; RODRIGUES, 2015), gerando a conversação e, posteriormente, o engajamento. Ou seja, mesmo não sendo capaz de provocar interação por si só, o uso dos emoticons contribui para o entendimento da interação pela via da conversação.

O fluxo da interatividade em um ambiente de conversação é dinâmico, o que dificulta a previsão dos comportamentos, mediante as reações que são emitidas rapidamente (PRIMO, 2000; TOALDO; RODRIGUES, 2015). Por isso, é necessário levar em consideração o que Motta (2016) apontou como momento de abrangência de dados, no qual temos uma profusão de comentários, fotos, vídeos e textos contendo ideias, opiniões e posicionamentos, à mercê da reação imediata daqueles que consomem, agora identificadas pelas seis reações dos emoticons, positivas, negativas e neutras.

Shirky (2011, p. 186) ajuda a refletir sobre esse ambiente de reações e interações na medida em que enfatiza:

Nosso ambiente de mídia (ou seja, nosso tecido conjuntivo) mudou. Num histórico piscar de olhos, passamos de um mundo com dois modelos diferentes de mídias - transmissões públicas por profissionais e conversas privadas entre pares de pessoas - para um mundo no qual se mesclam comunicação social pública e a privada, em que a produção profissional e a amadora se confundem e em que a participação pública e voluntária passou de inexistente para fundamental.

Primo (2008) já apontou que em um ambiente de mídia social se faz necessário avaliar a qualidade do relacionamento, em que um reage à ação do outro, mostrando muitas vezes intensidade, força ou potência. É a partir dessa reflexão que chegamos ao engajamento, como uma reação de intensidade aquilo que consome, antes impossível de ser identificada apenas pelo botão "curtir”.

Observando esse ambiente interativo e reativo, no qual as emoções podem ser identificadas, mensuradas e agrupadas, o engajamento poderá ser obtido a partir do processo interativo, oriundo das repetições das ações, refletindo as motivações dos grupos sobre a demarcação das reações (ALMEIDA; ALMEIDA; LIMA, 2015). Carvalho e Matos (2016) apontam que, para haver engajamento, deve haver interação efetiva entre consumidores e marcas ou empresas. Em relação ao Facebook, isso poderia ser medido também pelas curtidas, pois curtidas, comentários e compartilhamentos são variáveis aceitas como fatores mensuráveis do engajamento. $\mathrm{O}$ engajamento pode ser analisado a partir de interações frequentes, pois sua compreensão está ligada à qualidade das reações, a qual está relacionada à interação entre eles (RECUERO, 2013; TOALDO; RODRIGUES, 2015).

Como parte de uma discussão sobre o engajamento por meio das conversações a partir do uso dos emoticons, devemos lembrar que as reações disponibilizadas podem ser agrupadas como positivas, negativas ou neutras, abrindo campo para a análise de sentimento como uma forma de qualificar o engajamento. A análise de sentimento pode ser utilizada para avaliar e classificar opiniões, agrupando entre o que é positivo, negativo ou neutro (SALUSTIANO, 2016). Portanto, se os emoticons possibilitam a diversidade das reações como forma de expressão das emoções, é possível classificá-los dentro da perspectiva da análise de 
sentimento. Dessa forma, convergimos com apontamentos de Toaldo e Rodrigues (2015), os quais afirmam que, dada a complexidade da discussão sobre a problemática do engajamento a partir das interações, há necessidade de investigar continuamente esse fenômeno, tendo como objeto as mídias sociais.

\section{PROCEDIMENTOS METODOLÓGICOS E ANÁLISE DOS RESULTADOS}

Esta é uma pesquisa exploratória, aplicada a partir de um questionário estruturado desenvolvido para agrupar e medir a intensidade dos emoticons mediante a percepção do consumidor sobre a representação de cada reação. Foram coletados 157 respondentes. Para esta pesquisa não se fez necessária a coleta de um perfil psicográfico ou demográfico, portanto, o que nos interessava era coletar informações sobre o uso dos emoticons, independentemente de idade, sexo ou estilo de vida.

Partimos de três objetivos específicos de análise: (i) agrupar os emoticons pelas três categorias principais da análise de sentimento (negativo, neutro e positivo); (ii) medir a intensidade dos emoticons em relação ao tipo de sentimento pela percepção de uso do consumidor; e (iii) escalonar os emoticons entre a polaridade do mais positivo ao mais negativo, a fim testar a organização de uma escala ordinal de intensidade.

Para Motta (2016), a análise de reações e interações em ambiente de mídias sociais passa por emoções básicas, como felicidade, raiva, tristeza e medo, e isso demanda, por parte dos anunciantes publicitários, métricas para entender melhor o consumidor nos ambientes de mídia social (FACEBOOK..., 2017c). Marcas investem em ações de mídias sociais tentando usufruir da interatividade com seus consumidores, a fim de promover o engajamento com eles (TOALDO; RODRIGUES, 2015), mas ainda se sabe pouco sobre a relação de engajamento em torno de uma marca nas mídias sociais, da necessidade de se ter dados mais consolidados sobre o processo de relacionamento. Recuero (2013) e Toaldo e Rodrigues (2015) comentam ainda que tais medidas, por si só, revelam muito pouco sobre a situação de uma marca nas redes sociais.

É preciso aliar as informações métricas a uma investigação mais profunda e próxima dos usuários, pois apenas medir a audiência em torno de quantos curtiram, comentaram ou compartilharam diz muito pouco a respeito do que realmente está acontecendo com uma marca dentro das mídias sociais (RECUERO, 2013). Toaldo e Rodrigues (2015) questionam se o fato de um consumidor "curtir" ou mesmo comentar um conteúdo de uma marca significa que há um engajamento. Dessa forma, a análise dos dados desta investigação buscará elementos que ajudem a preencher essa lacuna sobre engajamento nas mídias sociais.

O primeiro questionamento foi em relação ao uso dos emoticons. Todos os respondentes afirmaram ter usado ao menos uma vez um dos emoticons do Facebook para interagir na mídia social. Em relação à frequência de uso, percebemos que mais da metade dos respondentes usaram todos os emoticons em pelo menos uma situação, evidenciando o hábito de expressar a reação e não simplesmente interagir com um “curtir”, como podemos observar pelo Gráfico 1.

Os dados mostram que há uma supremacia do uso do "curtir", seguido pelo "amei”, e a reação menos utilizada foi a "grr”, equivalente à emoção de raiva, seguida pelo emoticon que corresponde à emoção de espanto, o "uau”. Em relação às motivações para o uso dos emoticons, 
os respondentes afirmaram utilizá-los com a finalidade de manifestar a reação em função do sentimento sobre o conteúdo ao qual foi exposto para interagir (96\%), enquanto apenas $4 \%$ disseram que utilizaram porque viram outras pessoas tendo esse comportamento. Já em relação ao posicionamento de aprovação ou reprovação, foi possível notar que os respondentes estão mais propensos a manifestar aprovação do que reprovação, o que indica um comportamento positivo (Gráfico 2).

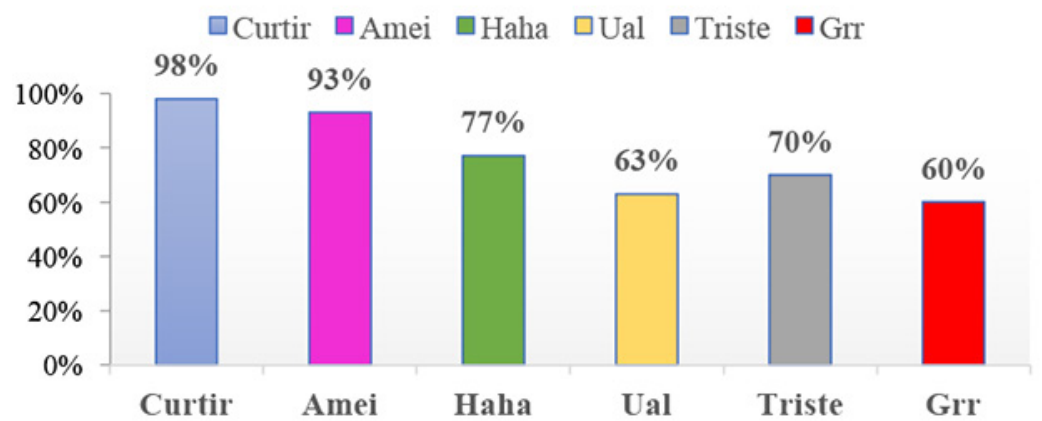

Gráfico 1. Utilização dos emoticons em relação à amostra. Fonte: Elaborado pelo autor (2017)

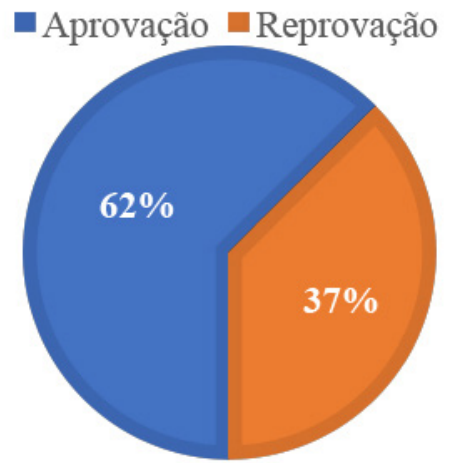

Gráfico 2. Uso dos emoticons em função de aprovar ou reprovar o conteúdo. Fonte: Elaborado pelo autor (2017)

Em seguida, foram feitos três agrupamentos de questões. O primeiro deles é sobre a adequação do tipo de reação aos emoticons (Figura 1), seguido pelo emoticon em relação ao tipo de sentimento (Gráfico 3) e a polaridade pela qual o emoticon estabelece um sentimento mais positivo ou negativo (Gráfico 4), e resumidamente chegamos ao Quadro 1, que estabelece a organização dos emoticons mediante aos agrupamentos de questões.

A partir dos dados obtidos em percentual e da organização do Quadro 1, percebemos que dois emoticons tinham suas posições bem demarcadas, caso de "amei" e "grr". O "amei" apareceu como um emoticon que pode ser considerado dentro do grupo dos positivos para 98\% dos respondentes, superando o "curtir", que teve índice de $81 \%$. Isoladamente, quando foi questionado qual tipo de sentimento o "amei" provoca, mais uma vez ficou evidente o sentimento positivo: 99\% dos respondentes o apontaram como positivo. Finalmente, quando foi questionado qual dos emoticons tinha maior intensidade em relação à representação de um sentimento positivo, o "amei” obteve $88 \%$ das respostas. No sentido contrário, para sentimento negativo o "grr" obteve os maiores índices, chegando a $94 \%$ no agrupamento, $94 \%$ no 
individual e $82 \%$ na intensidade, demarcando-o como a reação mais negativa de todas. Assim, distribuímos os emoticons em três conjuntos de sentimentos, positivo, negativo e neutro, em função dos resultados obtidos (Figura 3).

\begin{tabular}{|l|l|}
\hline \multicolumn{2}{|c|}{ EMOTICONS EM RELAÇÃO AOS SENTIMENTOS } \\
\hline Emoticons que são considerados reações positivas & Amei, curtir, uau, haha \\
\hline Emoticons que são considerados reações negativas & Grr, triste, haha \\
\hline Emoticons que são considerados reações neutras & Curtir, uau, haha \\
\hline \multicolumn{2}{|c|}{ TIPO DE SENTIMENTO EM RELAÇÃo AO EMOTICON } \\
\hline Emoticon "curtir" & Neutra \\
\hline Emoticon "amei" & Positiva \\
\hline Emoticon "uau" & Positiva \\
\hline Emoticon "haha" & Positiva \\
\hline Emoticon "triste" & Negativa \\
\hline Emoticon "grr" & Negativa \\
\hline \multicolumn{2}{|c|}{ INTENSIDADE DO SENTIMENTO EM RELAÇÃO AO EMOTICON } \\
\hline Emoticon com maior intensidade positiva & Amei \\
\hline Emoticon com maior intensidade negativa & Grr \\
\hline
\end{tabular}

Quadro 1. Resumo dos agrupamentos dos emoticons.

Fonte: Elaborado pelo autor (2017).

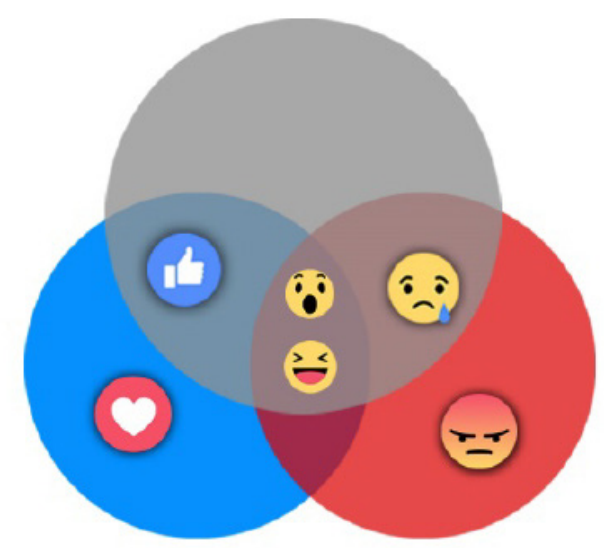

Positivo Neutro Negativo

Figura 3. Agrupamento dos emoticons em relação ao tipo de sentimento Fonte: Elaborado pelo autor (2017).

É perceptível os dois emoticons mais polarizados são "amei” e o "grr", porém a Figura 1 mostra uma intersecção de sentimentos em relação aos demais. O "curtir" ficou agrupado como um sentimento tanto positivo quanto neutro. Mesmo quando isoladamente foi questionado qual era o sentimento mais adequado, houve quase um empate, tendo 50,5\% dos respondentes posicionando-o como positivo, $48,5 \%$ como neutro, e apenas $1 \%$ como negativo. "Haha" e "uau" foram os que mostram índices menos concentrados para uma demarcação de sentimento; mesmo assim, permanecem entre o positivo e o neutro. Entretanto, o "haha" teve 3\% dos respondentes colocando-o no grupo dos emoticons negativos; quando 
isolado, $4 \%$ o posicionaram como negativo e $1 \%$ o atribuíram como o mais negativo dos emoticons na questão sobre intensidade.

Apesar de os índices não serem tão altos, é possível questionar a variedade de sentimentos que uma risada pode conter, tanto como de felicidade, que pode ser considerado positivo, quanto de ironia, que pode ser considerada como negativa, tirando desse emoticon um posicionamento claro. Dados estes que podemos observar e comparar com o Gráfico 3, que mostra a proporção de sentimentos para cada emoticon.

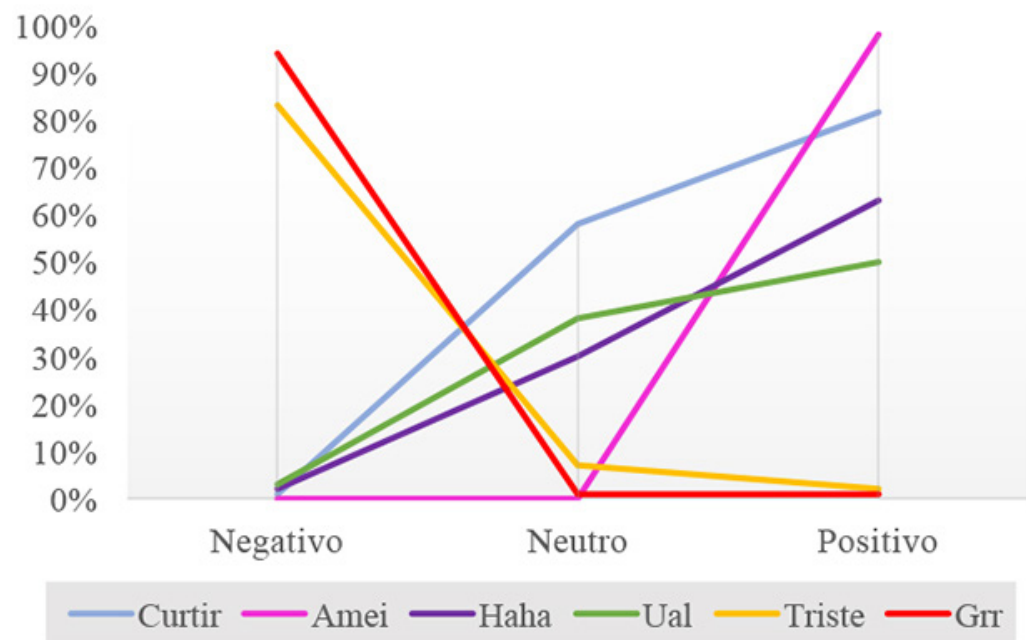

Gráfico 3. Relação entre o uso dos emoticons e o tipo de sentimento Fonte: Elaborado pelo autor (2017).

Após analisar em conjunto e isoladamente os emoticons em relação aos tipos de sentimentos nos quais eles se encaixam, o último passo era medir qual deles tinha maior intensidade positiva e negativa para expressar uma opinião (Gráfico 4).

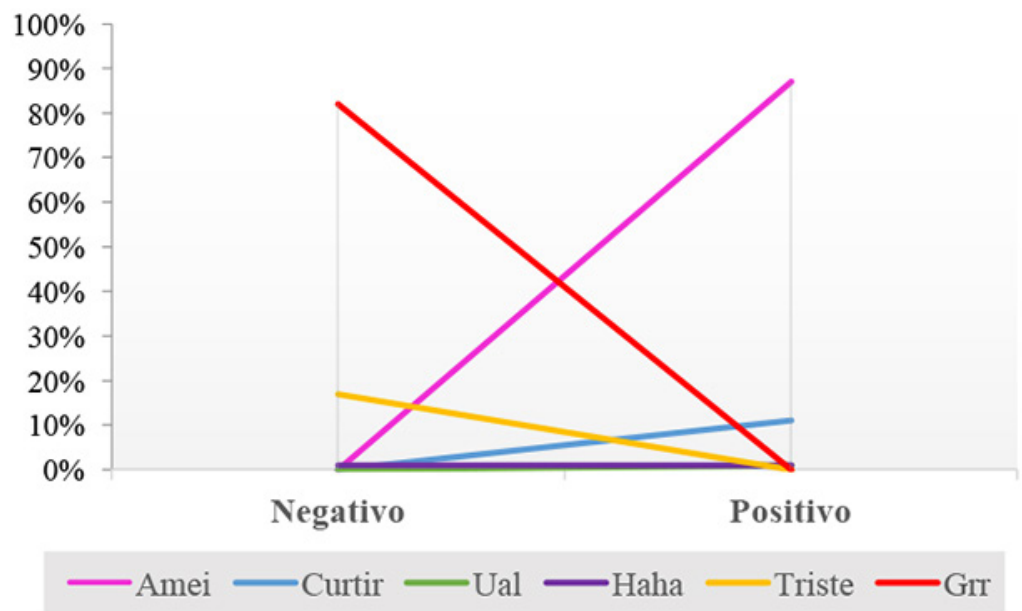

Gráfico 4. Intensidade dos emoticons em relação ao tipo de sentimento. Fonte: Elaborado pelo autor (2017)

"Amei" e "grr" são os emoticons com maiores cargas de sentimento, polarizados entre o positivo e negativo. Logo, é possível afirmar que aprovação ou reprovação total de um conteúdo passa pelo o uso de um 
deles. No entanto, não foi possível criar uma escala de intensidade que mostrasse claramente a passagem do emoticon mais positivo para o negativo como nos casos dos demais, em que o "curtir" passa por positivo e neutro e o "haha", entre positivo, neutro e negativo.

Finalmente, com essa análise podemos fazer as seguintes asserções:

- "Amei" e "grr" têm as cargas de sentimentos mais definidas e diametralmente opostas, entre positivo e negativo, respectivamente.

- "Curtir" é um sentimento positivo, porém tendendo à neutralidade, o que pode revelar a fraqueza do seu entendimento - pois o consumidor pode apenas ter clicado nesse emoticon pelo fato de ser o primeiro na ordenação dada pelo Facebook ou por que houve apenas uma demarcação de presença na conversação, sem a intenção de expor o sentimento.

- "Haha" e "uau" podem ser tanto positivos quanto neutros ou negativos, e se fará necessário analisar a tendência positiva ou negativa do conteúdo postado e articular com os comentários para entender melhor seu significado, podendo mudar conforme o contexto e assumir a ideia de ironia, por exemplo.

- Não é possível criar uma escala de intensidade entre os emoticons, apenas agrupá-los em relação ao tipo de sentimento em que se encaixam. Mesmo assim, esses agrupamentos se mostram contaminados, principalmente em relação a "curtir", "haha" e "uau".

- Os emoticons melhoram a percepção do sentimento expresso pelo consumidor quando o utiliza em relação a um conteúdo e são mais uma variável para se entender o engajamento, pois estará mais engajado positivamente aquele que usar o "amei” em vez do “curtir”, porque há uma intensidade clara de sentimento positivo para o consumidor, por exemplo.

\section{CONSIDERAÇÕES FINAIS}

Esta pesquisa partiu do questionamento sobre como os emoticons, as cinco reações criadas pelo Facebook para melhorar a forma de expressão dos consumidores em relação ao processo de interatividade com os conteúdos consumidos, poderiam ser agrupados e analisados em relação ao sentimento e ao engajamento que podem produzir.

Ficou claro na pesquisa que a demarcação e a intensidade se dão pelos emoticons "amei" e "grr", e os demais transitam entre os tipos de sentimentos, podendo ser mais ou menos intenso dependendo do conteúdo e da visão daquele que utiliza esses símbolos para expressar sua emoção ou seu posicionamento. Os respondentes deixaram claro que utilizam com alta frequência os emoticons com o objetivo de expor sua emoção, não apenas como um ato de interatividade despretensiosa. Isso ajuda nos processos de análise de engajamento em mídias digitais, contribuindo positivamente para entender o grau de envolvimento do consumidor com determinado conteúdo, empresa ou marca.

Em relação as limitações desta pesquisa, destacamos o volume de respondentes, que quanto maior for, mais consolidados serão os resultados. Provocamos como desdobramentos para a continuidade e ampliação deste estudo: 
- Agregar questões de perfis demográficos a fim de entender se há diferenças no uso dos emoticons mediante caraterísticas psicográficas.

- Ampliar as questões com foco no uso de "haha" e "uau" para entender melhor o comportamento dos consumidores.

- Analisar como os conteúdos podem interferir no processo de uso dos emoticons e como os consumidores se sentem engajados ao utilizar cada uma dessas reações.

Estudos sobre engajamento do consumidor em mídias sociais têm fôlego para muitas discussões, tanto em relação a quem produz o conteúdo em mídia social quanto àqueles que são tocados pelos conteúdos e interagem, a fim de entender melhor as implicações sociais e mercadológicas do processo de conversação e colaboração por meio das mídias sociais.

Este não é um ponto final sobre o estudo dos emoticons para analisar o comportamento do consumidor em relação à sua interação por meio das mídias sociais. Espera-se que esta pesquisa possa contribuir para mais estudos sobre a temática do consumo de mídias sociais, assim como que também seja um indicador para estudos de engajamento de audiências e públicos-consumidores.

\section{REFERÊNCIAS}

102 MILHÕES de brasileiros compartilham seus momentos no Facebook todos os meses. Facebook para Empresas, Menlo Park, 19 abr. 2016. Disponível em: <https://goo.gl/S7Bfsu>. Acesso em: 20 jun. 2017.

ALMEIDA, R. B.; ALMEIDA, V. M. C.; LIMA, D. F. P. Comunidades de marca de fantasy sports games: identificação, engajamento, intenção de continuidade e valor da marca do patrocinador. Brazilian Journal of Marketing, São Paulo, v. 14, n. 1, p. 33-48, jan.-mar. 2015.

"AMEl", "uau", "grr": Facebook lança novos botões para interagir com o conteúdo. GaúchaZH Digital, Porto Alegre, 24 fev. 2016. Disponível em: <https://goo.gl/dZ9atC>. Acesso em: 23 jan. 2018.

CARNAVAL teve 63 milhões de pessoas no Facebook e 21 milhões no Instagram falando sobre a folia. Facebook para Empresas, Menlo Park, 7 mar. 2017. Disponível em: <https:// goo.gl/cT18R6>. Acesso em: 20 jun. 2017.

CARVALHO, A. L.; MATOS, E. B. M. Engajamento no Facebook: uma análise exploratória em um perfil varejista. In: ENCONTRO NACIONAL DA ASSOCIAÇÃO NACIONAL DE PÓS-GRADUAÇÃO E PESQUISA EM ADMINISTRAÇÃO, 40., 2016, Rio de Janeiro. Anais... Rio de Janeiro: Anpad, 2016. p. 1-20.

CASTELLS, M. O poder da comunicação. São Paulo: Paz e Terra, 2015.

FACEBOOK comemora 5 milhões de anunciantes ativos com novidades para pequenas empresas. Facebook para Empresas, Menlo Park, 10 abr. 2017a. Disponível em: <https:// goo.gl/6xXCvD>. Acesso em: 1ํ jul. 2017.

FACEBOOK é eleito como a plataforma mais admirada do mercado brasileiro. Facebook para Empresas, Menlo Park, 16 fev. 2017b. Disponível em: <https://goo.gl/Rr1ZQ7>. Acesso em: 16 fev. 2017

FACEBOOK anuncia novas parcerias para garantir maior transparência nas medições. Facebook para Empresas, Menlo Park, 31 jan. 2017c. Disponível em: <https://goo.gl/ FTfLVV>. Acesso em: 20 jun. 2017.

FACEBOOK revela que 2 em cada 3 pessoas acima dos 60 acessam a plataforma via celular. Facebook para Empresas, Menlo Park, 3 mar. 2017d. Disponível em: <https://goo. gl/4BTHGg>. Acesso em: 20 jun. 2017. 
MOTTA, C. Relacionamento e monitoramento. In: SILVA, T.; STABILE, M. (Orgs.). Monitoramento e pesquisa em mídias sociais: metodologias, aplicações e inovações. São Paulo: Uva Limão, 2016. p. 105-120.

NOAWK, M.; SPILLER, G. Agora sua marca pode alcançar até 2 bilhões de pessoas por mês no Facebook. Facebook Business, Menlo Park, 27 jun. 2017. Disponível em: <https://goo.gl/ nHH8JS >. Acesso em: 1ํ jul. 2017.

ORTEGA, R. Descubra a origem do botão curtir, do Facebook. Superinteressante, São Paulo, 31 out. 2016. Disponível em:<https://goo.gl/6LR5R6>. Acesso em: 29 jun. 2017.

PAIVA, V. L. M. O. A linguagem dos emojis. Trabalhos em Linguística Aplicada, Campinas, V. 55, n. 2, p. 379-399, maio-ago. 2016

PRIMO, A. O aspecto relacional das interações na web 2.0. In: ANTOUN, H. (Org.). Web 2.0: participação e vigilância na era da comunicação distribuída. Rio de Janeiro: Mauad, 2008. p. 101-122.

Interação mútua e interação reativa: uma proposta de estudo. Revista da Famecos, n. 12, p. 81-92, jun. 2000.

Engajamento × audiência no Facebook: uma breve discussão. Raquel Recuero, [S.I.], 7 mar. 2013. Disponível em: <https://goo.gl/LLoYTd>. Acesso em: 20 jun. 2017.

. Curtir, compartilhar, comentar: trabalho de face, conversação e redes sociais no Facebook. Verso e Reverso, São Leopoldo, v. 28, n. 68, p. 114-124, maio-ago. 2014.

RICO, O. A. S. Comunicação midiática e consumo de afetos: narrativas sobre protestos e ocupações contra a Reorganização Escolar em São Paulo. 2016. 178 f. Dissertação (Mestrado em Comunicação e Práticas de Consumo) - Escola Superior de Propaganda e Marketing, São Paulo, 2016.

SALUSTIANO, S. Análise de sentimento. In: SILVA, T.; STABILE, M. (Orgs.). Monitoramento e pesquisa em mídias sociais: metodologias, aplicações e inovações. São Paulo: Uva Limão, 2016. p. 29-52.

SHIRKY, C. A cultura da participação: criatividade e generosidade no mundo conectado. Rio de Janeiro: Jorge Zahar, 2011.

SOARES, F. R.; MONTEIRO, P. R. R. Marketing digital e marketing de relacionamento: interação e engajamento como determinantes do crescimento de páginas do Facebook. Navus, Florianópolis, v. 5, n. 3, p. 42-59, jul.-set. 2015

TEEHAN, G. Reactions: not everything in life is likable. Facebook Design, [S.I.], 24 fev. 2016. Disponível em: <https://goo.gl/UiLYej>. Acesso em 20 jun. 2017.

TOALDO, M. M.; RODRIGUES, A. I. Interação e engajamento entre marcas e consumidores/ usuários no Facebook. In: CONGRESSO BRASILEIRO DE CIÊNCIAS DA COMUNICAÇÃO, 38., Rio de Janeiro, 2015. Anais... São Paulo: Intercom, 2015. p. 1-15.

TOP sites in Brazil. Alexa, Seattle, 2017. Disponível em: <https://goo.gl/qdBew4>. Acesso em: 1ำ jul. 2017.

TUBENCHLAK, D. B. et al . Motivações da comunicação boca a boca eletrônica positiva entre consumidores no Facebook. Revista Administração Contemporânea, Rio de Janeiro, v. 19, n. 1, p. 107-126, jan.-fev. 2015

ZANDAVALLE, A. C. O mercado de inteligência de mídias sociais. In: SILVA, T.; STABILE, M. (Orgs.) Monitoramento e pesquisa em mídias sociais: metodologias, aplicações e inovações. São Paulo: Uva Limão, 2016. p. 11-28. 